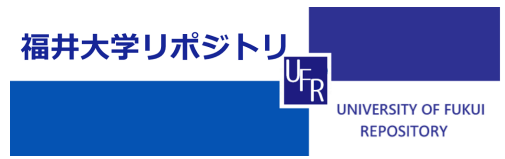

$\mathrm{Cl}$ oni ng, sequence anal ysi s, and expressi on of the genes encoding I ytic functions of Bact er i ophage Fg1e

\begin{tabular}{|l|l|}
\hline 著者 & $\begin{array}{l}\text { OK Nasaya, KAK KAWA Naki ko, YAMADA Kazuyo, } \\
\text { TAKETO Aki ra, KODAI RA Ken- I chi }\end{array}$ \\
\hline $\begin{array}{l}\text { j our nal or } \\
\text { publ i cat i on ti t l e }\end{array}$ & Gene - Anst er dam \\
\hline vol une & 176 \\
\hline number & $1-2$ \\
\hline page r ange & $215-223$ \\
\hline year & $1996-10$ \\
\hline URL & ht t p: //hdl . handl e. net /10098/1620 \\
\hline
\end{tabular}




\title{
Cloning, sequence analysis, and expression of the genes encoding lytic functions of Bacteriophage $\phi \mathrm{g} 1 \mathrm{e}$
}

\author{
Masaya Oki ${ }^{\text {a }}$, Makiko Kakikawa ${ }^{\text {a }}$, Kazuyo Yamada ${ }^{a}$, Akira Taketo ${ }^{\text {b }}$, Ken-Ichi Kodaira a , \\ ${ }^{a}$ Molecular Biology Group, Chemical and Biochemical Engineering, Faculty of Engineering, Toyama University, 3190, Gofuku, \\ Toyama, Toyama 930, Japan \\ ' Department of Biochemistry I, Fukui Medical School, Matsuoka, Fukui, Fukui 910-11, Japan
}

\begin{abstract}
The lysis genes of a Lactobacillus phage $\phi \mathrm{gle}$ were cloned, sequenced, and expressed in Escherichia coli. Nucleotide sequencing of a 3813-bp $\phi \mathrm{gle}$ DNA revealed five successive open reading frames (ORF), Rorf50, Rorf118, hol, and lys and Rorf175, in the same DNA strand. By comparative analysis of the DNA sequence, the putative hol product (holin) has an estimated molecular weight is $14.2 \mathrm{kDa}$, and contains two potential transmembrane helices and highly charged $\mathrm{N}$ - and $\mathrm{C}$-termini, resembling predicted holins (which are thought to be a cytoplasmic membrane-disrupting protein) encoded by other phages such as mv1 from Lactobacillus bulgaricus, $\phi \mathrm{adh}$ from Lactobacillus gasseri, as well as monocins from Listeria. On the other hand, the putative $\phi \mathrm{g} 1 \mathrm{e}$ lys product (lysin) of $48.4 \mathrm{kDa}$ shows significant similarity with presumed muramidase, known as a cell wall peptidoglycandegrading enzyme, encoded by the Lactobacillus phage mv1 and $\phi \mathrm{adh}$, the Lactococcus lactis phage $\phi$ LC3, and the Streptococcus pneumoniae phages $\mathrm{Cp}-1, \mathrm{Cp}-7$ and $\mathrm{Cp}-9$. When expressed in E. coli, the $\phi \mathrm{gle}$ lysin and/or holin decreased the cell turbidity significantly, suggesting that the $\phi \mathrm{gle}$ hol-lys system is involved in cytolytic process.
\end{abstract}

Keywords: Bacteriophage $\phi \mathrm{gle}$; Lactic acid bacteria; Lysin; Holin; Muramidase; DNA sequence

\section{Introduction}

Prevalence of lysogeny in various lactic acid bacteria has been reported (Davidson et al., 1990). For release of progeny particles from the host cell, such lysogenic phages appear to encode a set of enzymes, which degrade the host cell envelope consisting of several structural components such as peptidoglycan layer and cytoplasmic membrane, and the lysis genes seem to be expressed under a complicated control, as in the coliphage lambda system (for a review, see Young, 1992).

In several phages, the cytolytic process has been presumed to depend upon two phage-encoded lysis proteins. The one known as a holin inflicts lesions in the cytoplasmic membrane, through which the other lysis protein termed lysin can be efficiently released to the periplasm. The lysins belong to a group of mureindegrading enzyme (muramidase), and have been divided into several subgroups: lysozyme, glycosidase, amidase or endopeptidase (for reviews, see Young, 1992; Sable and Lortal, 1995).

Several presumptive lysins and holins have been reported from phages of lactic acid bacteria: $\phi$ adh from Lactobacillus gasseri (Henrich et al., 1995), mv1 and mv4 from Lactobacillus bulgaricus (Boizet et al., 1990), and $\phi$ LC3 (Birkeland, 1994) and Tuc2009 (Arendt et al., 1994) from Lactococcus lactis.

In contrast to coliphage lambda (Young, 1992; Campbell, 1994) and P2 (Ziermann et al., 1994), molecular details on the lytic pathway of the phages from lactic acid bacteria are still insufficient; thus structure, expression, function and enzymatic feature on the phage lysis genes mostly remain to be elucidated (Young, 1992; Sable and Lortal, 1995).

Recently, we isolated a new Lactobacillus phage, termed $\phi \mathrm{gle}$, which contains an about $42.5-\mathrm{kbp}$ DNA, and identified the major phage capsid genes (Kakikawa et al., 1996). In this report, we described structures of $\phi \mathrm{gle}$ genes related to cytolytic process, and their expressions in E. coli. 


\section{Materials and methods}

\subsection{Bacteria, phage, and plasmids}

The lysogenic Lactobacillus strain G1e and its temperate phage $\phi \mathrm{g} 1 \mathrm{e}$ were originally isolated in our laboratory (Kakikawa et al., 1996), and were propagated in M17 broth (Terzaghi and Sandine, 1975). The E. coli vector plasmids pUC18, pUC118, and pUC119, and their host XL1-blue and CK111 recA lac ${ }^{+}$were from our laboratory stock (Kodaira et al., 1992), and were propagated in LB or 2YT broth (Sambrook et al., 1989).

\subsection{Analysis of DNA}

Cloning and sequencing analyses of $\phi \mathrm{g}$ le DNA were carried out essentially as described by Kakikawa et al. (1996). Recombinant plasmids were introduced into E. coli XL1-blue by $\mathrm{Ca}^{2+}$-dependent transformation or electroporation (Taketo, 1988). For DNA sequencing, various deletion clones were constructed from several series of restriction library from $\phi \mathrm{g} 1 \mathrm{e}$ DNA (Kakikawa et al, 1996) by exonuclease digestion (Kodaira et al., 1994a). The DNA sequence was determined by the chain termination method (Sanger et al., 1977). All other procedures were performed as described previously (Kodaira et al., 1994b).

\subsection{Expression of $\phi g 1$ genes in $\mathrm{E}$. coli}

E. coli XL1-blue carrying a recombinant plasmid, which contains the $\phi g 1$ e genes, was grown at $25^{\circ} \mathrm{C}$ in LB medium containing ampicillin $(60 \mu \mathrm{g} / \mathrm{ml})$. When the $\mathrm{A}_{660}$ of the culture had reached 0.3 , the growth temperature was shifted up to $37{ }^{\circ} \mathrm{C}$ with or without addition of isopropyl- $\beta$-D-thiogalactopyranoside (IPTG) (final concentration, $1 \mathrm{mM}$ ), and the cell growth was monitored by measuring the change in $\mathrm{A}_{660}$. Activity of $\beta$ galactosidase was determined as follows: $E$. coli CK 111 carrying a plasmid pL19PPR was grown at $25^{\circ} \mathrm{C}$ in LB medium containing ampicillin $(60 \mu \mathrm{g} / \mathrm{ml})$, and shifted to $37^{\circ} \mathrm{C}$ when the $\mathrm{A}_{660}$ of the culture had reached 0.3. At intervals, an aliquot of the culture was removed, centrifuged, and the supernatant fluid was reserved. $\beta$ Galactosidase activity in the supernatant was assayed at $37^{\circ} \mathrm{C}$ using $\mathrm{O}$-nitrophenyl- $\beta$-galactoside $(0.7 \mathrm{mM})$ in $0.1 \mathrm{M}$ sodium phosphate buffer ( $\mathrm{pH} 7.3$ ). The activity was followed by measuring $A_{420}$ of nitrophenol released.

All other methods for in vivo experiments were as described previously by Kodaira et al. (1992).

\subsection{Enzymes and biochemicals}

Restriction enzymes, phage T4 DNA ligase, and alkaline phosphatase (calf intestine) were purchased from
Takara Shuzo (Kyoto) and Nippon Gene (Toyama). Buffers for each enzymes were as recommended by the manufacturers.

$\left[\alpha-{ }^{32} \mathrm{P}\right] \mathrm{dCTP}$ was from NEN. All other materials were as described previously by Kodaira et al. (1992).

\section{Results and discussion}

\subsection{Sequence analysis of the phage $\phi g 1$ le lysis genes}

Bacteriophage $\phi \mathrm{gle}$ induced from a lysogenic Lactobacillus strain Gle has a double-stranded DNA of approximately $42.5 \mathrm{kbp}$. Recently, we have constructed a $\phi$ gle restriction map, and determined the nucleotide (nt) sequences of four structural genes, G, P, B, and $O$, which code for major capsid proteins (Kakikawa et al., 1996).

Downstream of the gene $O$, the extended sequencing analysis of a 3813-bp DNA revealed five ORFs Rorf 50 (153 bp), Rorf118 (357 bp), hol (429 bp), lys (1329 bp), and Rorf 175 ( $528 \mathrm{bp}$ ), in addition to a minor ORF Rorf94 (285 bp) and one truncated ORF Rorf 148 (Fig. 1). In Fig. 2, the DNA sequence of 3813 bp containing these ORFs (gene O through Rorf 148) is presented together with their predicted amino acid (aa) sequences. All the ORFs are encoded on one strand, and preceded by a potential ribosome binding sequence, which is in good agreement with those of several Lactobacillus (5'-AGGAGG-3', Pouwels and Leer, 1993) and Lactococcus (5'-AGAAAGGAGGT-3', Ludwig et al., 1985; Schouler et al., 1994) genes.

As described below, the two potential genes hol and lys are probably involved in bacterial cell lysis, and their putative products were termed holin and lysin, respectively. hol begins with ATG at nt position 978 (Fig. 2), and codes for a basic protein (holin) of 142 aa, whose estimated MW and $\mathrm{p} I$ are 9450 and 14.2, respectively. On the other hand, lys starts with GTG located at nt position 1390 (Fig. 2), and its putative product (lysin) of 422 aa $(48.4 \mathrm{kDa}$ ) is also basic (with 9.70 of $\mathrm{pl}$ ). lys has one more potential start codon (ATG) located at nt position 1432, although its ribosomal binding sequence $\left(5^{\prime}-\mathrm{GGA}^{\prime} 3^{\prime}\right)$ is very short (Fig. 2).

In other three ORFs Rorf50, Rorf118, and Rorf 175 as well as a minor ORF Rorf 94 , their putative products show no significant similarities to other proteins, and their functions in the $\phi \mathrm{gle}$ development have not been ascertained. In gpRorf 175 , however, its middle regions shows a limited resemblance $(30 \%$ identical, $40 \%$ similar) to a lysis protein, named LysA, of coliphage P2, which has been predicted to play a role in the correct timing of lysis, although nonessential (Ziermann et al., 1994). gpRorf50 (50 aa) is very acidic (with 3.85 of pI), and has a leucine-rich hydrophobic N-terminus (Fig. 2). 


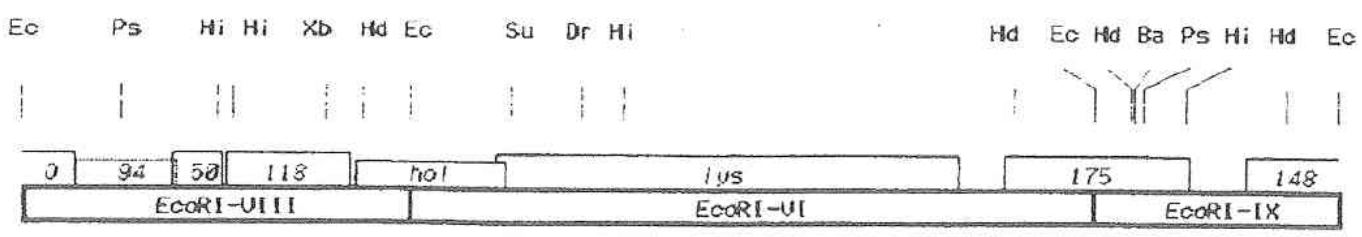

PL119PBL $(t)$
PL119KBL $(t)$
PL118EHL $(t)$
PL119KSUL $(t)$
PL118XDL $(t)$
PL118EDL $(t)$
PL118EHIL $(-)$
PL119PPR $(t)$
PL18DPR (t)
PL18DPRde1 $(t)$

DLIBEPR (-)

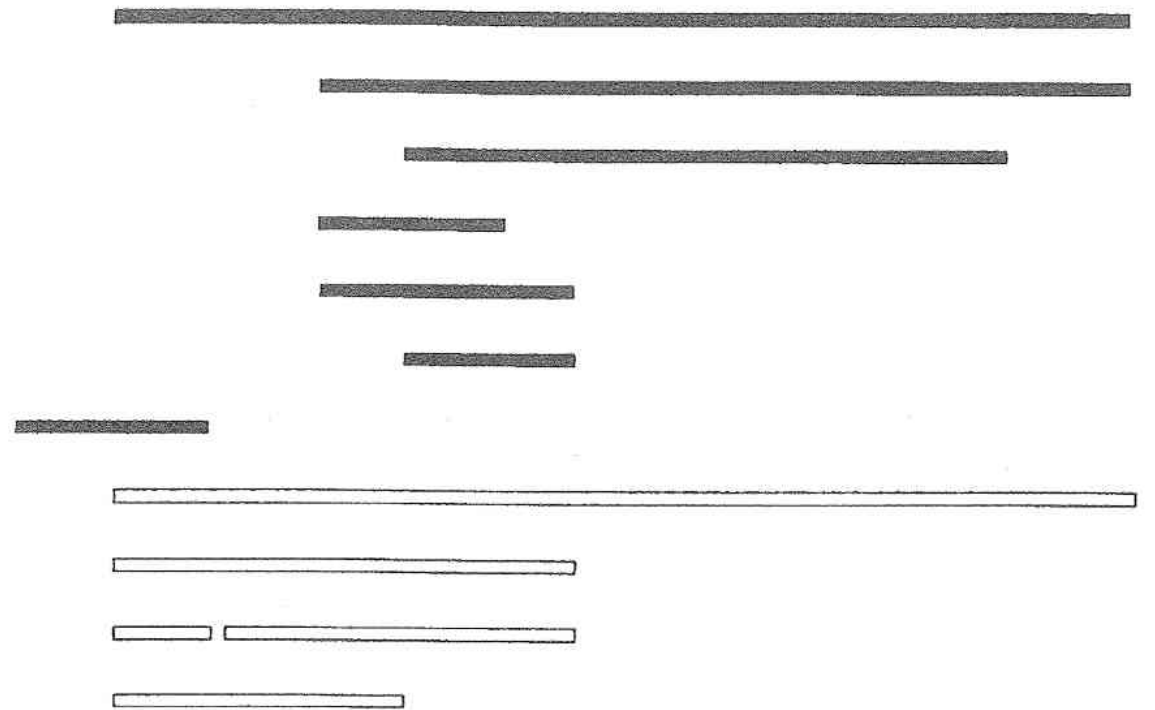

Fig. 1. Physical map of the $\phi$ gle lytic genes. The recombinant plasmids and their predicted lytic phenotypes are indicated. The construction of the recombinant plasmids is indicated in Table 1 . The closed boxes show the $\phi g$ le DNA inserts cloned under the lac Z' promoter. The lytic phenotype $(+$ or -$)$ was predicted by the decrease of $E$. coli cell turbidity as shown in Fig. 6. Ba, BamHI; Ec, EcoRI; Dr, Dral; Hd, HindIII; Hi, HincII; Ps, PstI; Su, Sau 3 AI; Xb, XbaI.

On the other hand, gpRorf148 has an arginine-rich N-terminus, which somewhat resembles the argininerich motif found in antiterminator proteins of coliphages lambda and $\phi 21$, and Salmonella typhimurium phage P22 (for a review, see Burd and Dreyfuss, 1994).

\subsection{Structural characteristics of the $\phi g$ le lysin}

$\phi \mathrm{gle}$ lysin shares significant similarity with presumptive muramidases encoded by the Lactococcus lactis phage $\phi$ LC3 (Birkeland, 1994) and Tuc2009 (Arendt et al., 1994), the Lactobacillus bulgaricus phage mv1 (Boizet et al., 1990) and mv4 (Dupont et al., 1993), the Lactobacillus gasseri phage $\phi$ adh (Henrich et al., 1995), the Streptococcus pneumoniae phage $\mathrm{Cp}-1, \mathrm{Cp}-7$ and Cp-9 (Garcia et al., 1990), the coliphage lambda (Sanger et al., 1982), and the fungus Chalaropsis (Fouche and Hash, 1978). For example, the similarity between the lysins of $\phi \mathrm{gle}$ and $\phi \mathrm{LC} 3$ is $31 \%$ identical and $52 \%$ equivalent.

In Chalaropsis, the two acidic residues $\mathrm{Asp}^{6}$ and $\mathrm{Glu}^{33}$ have been estimated to be pivotal for the muramidase activity (Fouche and Hash, 1978). N-terminus of $\phi \mathrm{g} 1 \mathrm{e}$ lysin has also identical aa residues, $\mathrm{Asp}^{36}$ and $\mathrm{Glu}^{67}$ (Fig. 3A), suggesting that an active center of $\phi$ gle lysin is localized in the $\mathrm{N}$-terminus (see Fig. 6C). Middle region of $\phi \mathrm{gle}$ lysin (in about 90 -aa region) contains four homologous regions with that of other phages such as $\phi \mathrm{adh}, \mathrm{mv} 4, \phi \mathrm{LC} 3$, and $\mathrm{Cp}-1$ (Fig. 3B). Henrich et al. (1995) have reported that these four regions, termed motif A, B, C, and D, may play some structural or functional roles. C-terminal half of $\phi \mathrm{g} 1 \mathrm{e}$ lysin is different from other lysins in both length and aa sequence (see Fig. 5). In the $\mathrm{C}$-terminus of $43 \mathrm{aa}, \phi \mathrm{g} 1 \mathrm{e}$ shares sequence similarity (19 aa identical, see Fig. 3 C) with $\phi \mathrm{LC} 3$. In $\phi$ LC3 (Birkeland, 1994), the 43-aa region has been suggested to be a functional domain involved in binding to the bacterial cell wall, possibly through recognition of the peptidoglycan moiety. Thus, $\phi \mathrm{g}$ le lysin seems to be composed of three modules: the N-terminus (termed module DE) functioning as an active center of the enzyme; the middle region (module $\mathrm{ABCD}$ ); the C-terminal half (module MEM) acting as a recognition site(s) of cell wall (Fig. 5). As pointed out by Birkeland (1994), exchange of these modular units may be an important principle in lysis protein evolution. 

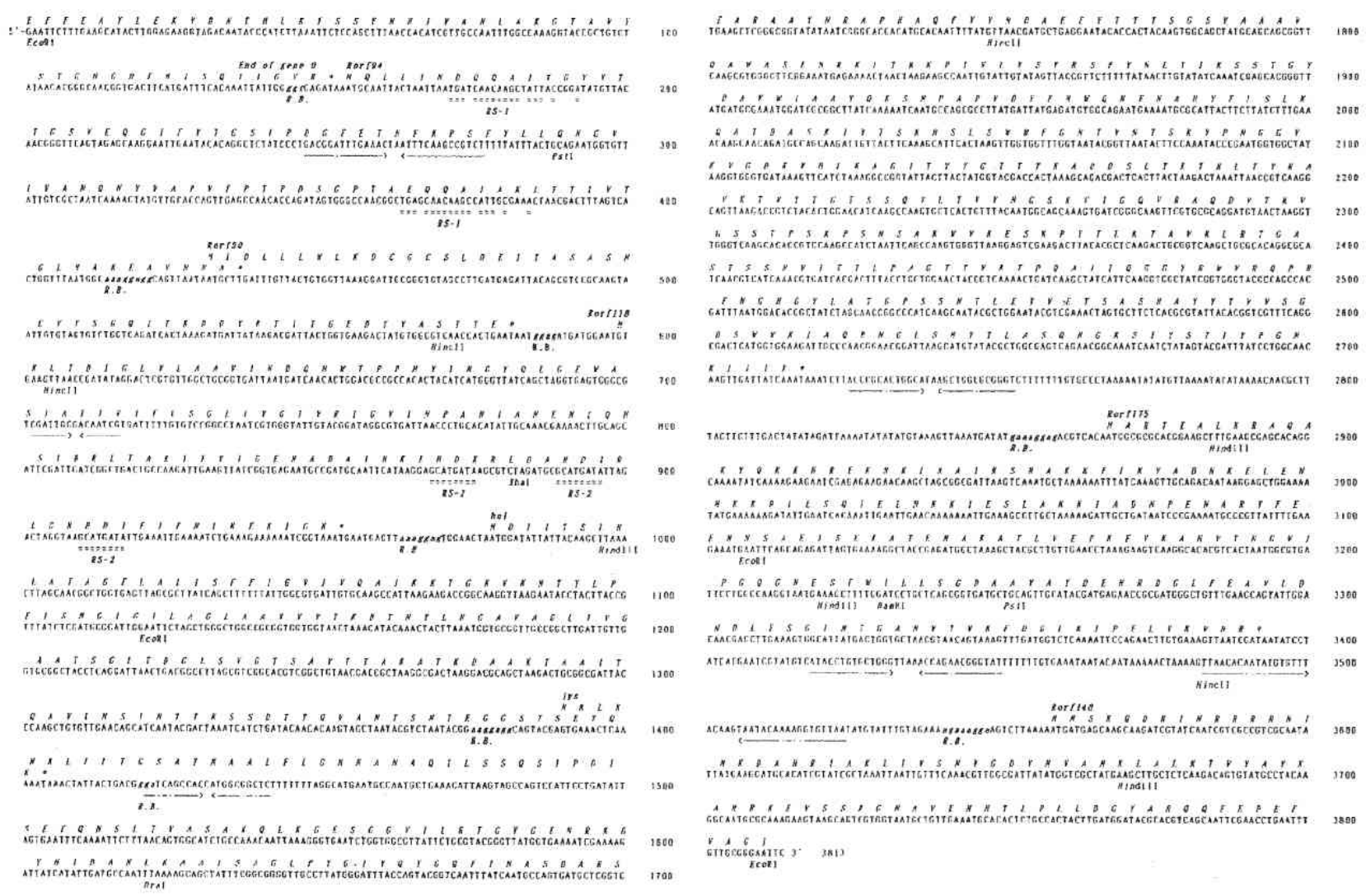

Fig. 2. DNA and predicted amino acid sequences of genes 0 , Rorf 94 , Rorf50, Rorf118, hol, lys, Rorf175, and Rorf148. Asterisks indicate stop codons. Arrows show inverted repeats. Bold italic lower letters indicate putative ribosome binding sites (R.B.). Dotted double lines present repeated sequences (RS). Restriction sites using the construction of the recombinant plasmids are shown as well.

\subsection{Structural characteristics of the $\phi g 1$ le holin}

$\phi$ gle holin shows high sequence similarity with other several predicted holins of phages (or monocins) from Listeria, which are thought to function as a second phage lysis protein (Zink et al., personal communication): e.g. more than 20 residues in a 58 -aa region of monocin holin (Zink et al., 1995) are identical to those of $\phi$ g1e holin (Fig. 4B).

Generally, holins encoded by phages are thought to be different in aa sequence, but their physical natures are predicted to be quite similar (Birkeland, 1994; Young, 1992). In the lambda system, the holin encoded by gene $\mathrm{S}$ is estimated to form lesions in the cytoplasmic membrane, through which the lysin encoded by gene $\mathrm{R}$ can be efficiently released to the periplasm (for a review, see Young, 1992).

Like lambda, $\phi \mathrm{g}$ le contains a pair of hydrophobic transmembrane-spanning domains of about 20 residues separated by a highly charged sequence, albeit different in aa sequence. The structural similarity between the potential holins from the phages $\phi \mathrm{gle}$, mvl (for a paper see Young, 1992), and $\phi$ adh (Henrich et al., 1995) is presented in Fig. 4A; a sequence comparison of holins between $\phi \mathrm{gle}$, monocin (Zink et al., 1995), and $\phi \mathrm{LC} 3$ is shown in Fig. 4B.

\subsection{Expression of the $\phi g 1$ le lysis genes in $\mathrm{E}$. coli}

To elucidate properties of the $\phi \mathrm{g} 1 \mathrm{e}$ lytic system, various DNA regions containing hol and/or lys were cloned into E. coli expression vector (pUC18, pUC118 or pUC119) under $\mathrm{p}_{\text {lac }}$ control, and expressed in E. coli XL1-blue. Physical maps of these recombinant plasmids are shown in Table 1 and Fig. 1: pL119PBL (containing Rorf50-Rorf118-hol-lys); pL119XBL (hol-lys); pL118EHL (lys); pL119XSuL (hol). XL1-blue cells carrying $\mathrm{pL} 119 \mathrm{PBL}$ grow at low temperature, but they can not multiply above $20{ }^{\circ} \mathrm{C}$ even without IPTG. XL1-blue bacteria harboring the recombinant, pL119XBL, pL118EHL, or pL119XSuL, can not grow above $25^{\circ} \mathrm{C}$, and the culture turbidity decreased significantly after a temperature shift up from 25 to $37^{\circ} \mathrm{C}$ (Fig. 6A). The decrease of the cellular turbidity caused by pL119XBL occurred at $90 \mathrm{~min}$ after the temperature shift up. pL118EHL and pL119XSuL also induced turbidity decrease after approximately $240 \mathrm{~min}$ at $37^{\circ} \mathrm{C}$, although the process was slow and incomplete when compared 
(A)

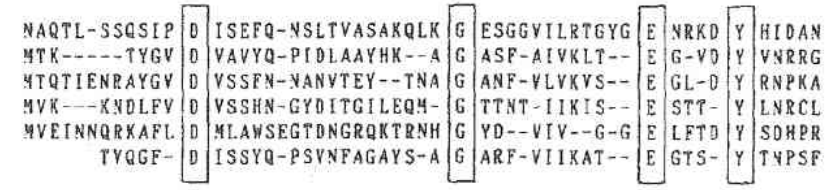

(B)

$\phi$ gle
ovl
$\phi$ adh
$C p-1$
$\lambda$
Chalaropsis

$\phi$ gle
v 1
$\phi$ adh
$\phi$ Le3
$c-1$

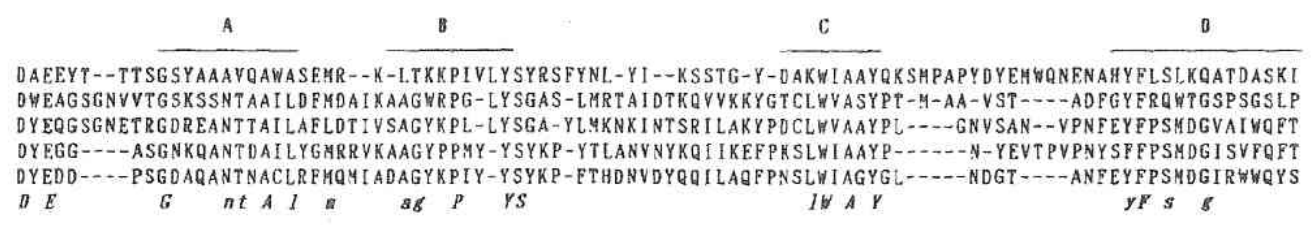

(C)

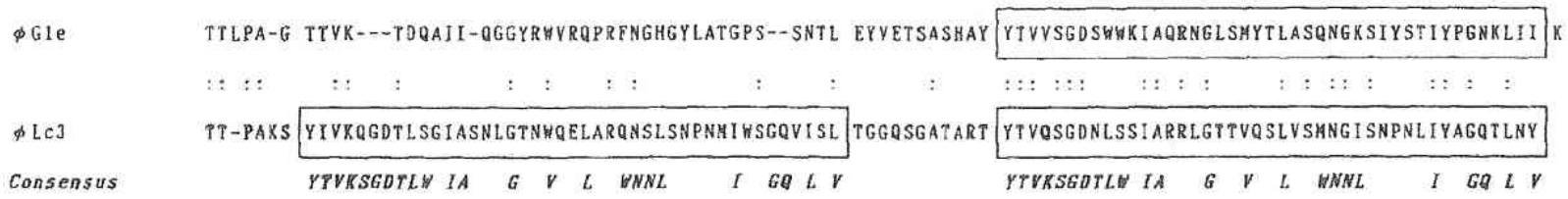

Fig. 3. Comparison of the $\phi \mathrm{g}$ le lysin with presumptive muramidases encoded by other phages. Dashes indicate positions with conservative substitutions. (A) The N-termini of the lysins of the phage $\phi \mathrm{g} 1 \mathrm{e}$ (this study), the L. bulgaricus phage mv1 (Boizet et al., 1990), the L. gasseri phage, padh (Henrich et al, 1995), the S. pneumoniae phage Cp-1 (Garcia et al., 1990), and the E. coli phage lambda (Sanger et al., 1982), and the muramidase of fungus Chalaropsis (Fouche and Hash, 1978). The aa residues conserved through the lysins are boxed. (B) The middle regions of the lysins of the phages $\phi \mathrm{g} 1 \mathrm{e}, \mathrm{mv1}, \phi \mathrm{adh}, \mathrm{Cp}-1$, and L. lactis phage $\phi \mathrm{LC} 3$ (Birkeland, 1994). The aa sequence and motifs A, B, C, and D are from Henrich et al. (1995). Consensus indicates the conserved aa residues; capital letters are conserved through the lysins. (C) C-termini of the lysins of the phages $\phi \mathrm{gle}$ and $\phi \mathrm{LC} 3$. Double colons represent the identical aa residues. Consensus shows conserved aa residues (Birkeland, 1994). The homologous a sequences between $\phi \mathrm{gle}$ and $\phi \mathrm{LC} 3$ (Birkeland, 1994) were boxed.

with pL119XBL. Preliminary Northern blot experiments have shown that transcripts of hol and/or lys of these recombinant plasmids accumulated at $37^{\circ} \mathrm{C}$, but not at $25^{\circ} \mathrm{C}$; this transcription at $37^{\circ} \mathrm{C}$ seems to be due to a leakiness of lacl $^{\mathrm{q}}$ control and/or a high copy number of the recombinant plasmid, suggesting that the decrease of cellular turbidity correlates well with the mRNA level of hol and/or lys (data not shown). This inference has been further supported by in vivo experiments using rifampicin and chloramphenicol, showing that both transcription and translation at $37^{\circ} \mathrm{C}$ are required for the decrease of cellular turbidity (data not shown).

When induced by IPTG at $37^{\circ} \mathrm{C}$ (Fig. 6A), each of the recombinants pL119XBL (hol-lys), pL119XSuL (hol), and PL118EHL (lys) led to a faster onset of turbidity decrease than that without IPTG; the rate of the decrease by hol-lys is more rapid than that by hol or lys, and the start of decrease by hol is earlier than that by lys, suggesting that holin can form lesions in the cell membrane, and can promote lysin-mediated cell lysis, as suspected in other holin-lysin systems of $\phi \mathrm{LC} 3$ (Birkeland, 1994) and фadh (Henrich et al., 1995) as well as lambda (Young, 1992).

In addition, several recombinants containing $\phi \mathrm{gle}$ hol and/or $l y s$, which are free from $p_{\text {lac }}$ control, were constructed (Table 1 and Fig. 1): pL119PPR (containing Rorf50-Rorf118-hol-lys); pL18DPR (Rorf50-Rorf118hol); pL18DPRdel (hol); pL18EPR (Rorf50-Rorf118); pL118EHiL (Rorf94). pL18DPRdel was derived from pL18DPR, and is missing a 36 -bp Hincll fragment extending from 3 '-terminus of Rorf 50 to 5 '-terminus of Rorf118. XL1-blue harboring each of these recombinants grew stably at $30^{\circ} \mathrm{C}$, but not at $37^{\circ} \mathrm{C}$ (Fig. 6B). Thus, pL119PPR exhibited an onset of turbidity decrease at 90 min after a temperature shift from $30^{\circ}$ to $37^{\circ} \mathrm{C}$. pL18DPR induced the decrease after approximately $180 \mathrm{~min}$ at $37^{\circ} \mathrm{C}$, albeit incomplete when compared with pL19PPR. On the other hand, pL18DPRdel did not reduce the cellular turbidity after the temperature shift up, but inhibited the cell growth significantly. A $\phi \mathrm{g} 1 \mathrm{e}$ 
(A)

$\phi$ gle

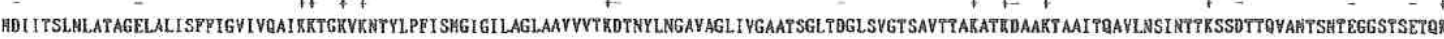

$\overline{t t t}_{\text {tittit }}$

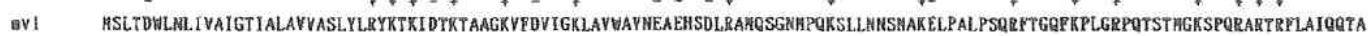

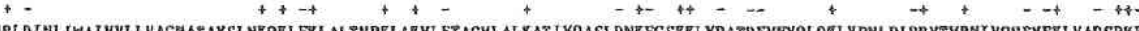

padh

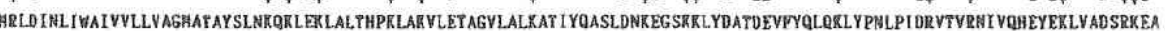

tht

(B)

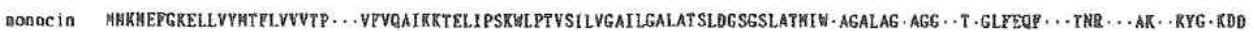

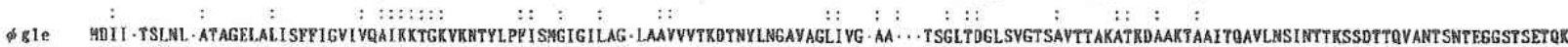

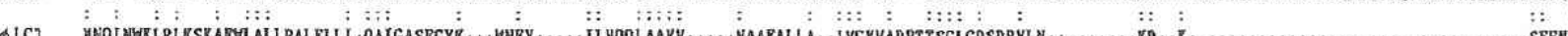

Fig. 4. Comparison of the $\phi \mathrm{gle}$ hol protein with presumptive holins encoded by other phages. +, basic aa; - , acidic aa. (A) Physical similarity between the holins of the phage $\phi \mathrm{gle}$ (this study), L. bulgaricus phage mv1 (Boizet et al., 1990), and L. gasseri phage $\phi$ adh (Henrich et al., 1995). Possible transmembrane domains are indicated by solid bars, and potential beta-turn regions are shown by lower case t's (Young, 1992). (B) Sequence homology between the holins of the phage $\phi \mathrm{gle}$ (this study), Listeria monocin (Zink et al., 1995), and the L. lactis phage $\phi$ LC3 (Birkeland, 1994). Double colons represent the identical aa residues. Dashes indicate positions with conservative substitutions.

$C P-1 \quad$ (339 аa)

两 1 (195 aa)

m 14 (297 a)

a d h (3it aa)

tg 1 (428 aа)

角 $1.63(429 \mathrm{ar})$

module
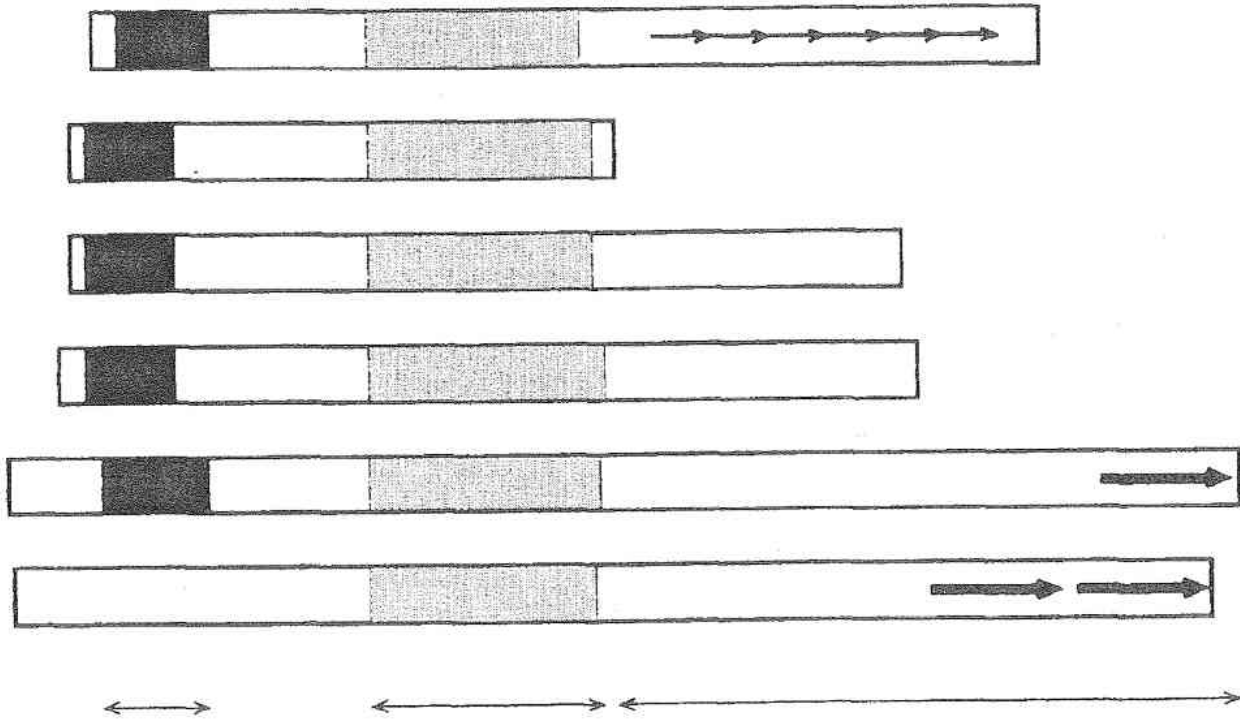

DE

$A B C D$

MEM

Fig. 5. Modules of the muramidases encoded by phages. The structures of the putative lysins of the phage $\phi \mathrm{g} 1 \mathrm{e}$ (this work), the $L$. bulgaricus phage mv1 (Boizet et al., 1990) and mv4 (Dupont et al., 1993), the L. gasseri phage $\phi$ adh (Henrich et al., 1995), the L. lactis phage $\phi$ LC3 (Birkeland, 1994), and the S. pneumoniae phage Cp-1 (Garcia et al., 1990) are compared. Three modules DE, ABCD, and MEM are shown in Fig. 3. The closed boxes show module DE. In $\phi \mathrm{LC} 3$ lysin, the two conserved residues Asp and Glu were not found in its N-terminus. The hatched boxes represent module ABCD (from Henrich et al, 1995). The six thin arrows in Cp-1 (Garcia et al., 1990) and the two thick arrows in $\phi$ LC3 (Birkeland, 1994) indicate repeated sequences. The arrow in $\phi \mathrm{gle}$ shows a region similar to that of $\phi \mathrm{LC} 3$ (see Fig. 3 ).

DNA region preceding hol may contain a transcriptional promoter(s) functioning in $E$. coli.

Computer-assisted analysis detected several promoterlike sequences ( -35 and -10 sequences) within Rorf94 and hol, which are similar to the presumptive promoters found in Lactobacillus (for a review see Pouwels and Leer, 1993) and E. coli (Harley and Reynolds, 1987). Alternatively, gpRorf50 and/or gpRorf118 may accelerate the turbidity decrease in combination with holin and/or lysin, as in the coliphage P2 (Ziermann et al, 
TABLE I

Plasmids

\begin{tabular}{|c|c|c|}
\hline Plasmid & Genotype or construct & Source or reference \\
\hline pUC18 & $A p^{r}, P_{l a c} l a c Z^{\prime}$ & Vieira and Messing, 1987 \\
\hline pUC118 & $A p^{\prime}, P_{\text {lac }}$ lac $Z^{\prime} \mathrm{M} 13$ origin & Vieira and Messing, 1987 \\
\hline pUC119 & $A p^{r}, P_{\text {lac }}$ lac $Z^{\prime} \mathrm{M} 13$ origin & Vieira and Messing, 1987 \\
\hline pL119PBL & $\begin{array}{l}\text { pUC1 19::2,938-bp PstI-Bam HI fragment from } \phi \mathrm{gle} \\
\text { (Rorf50, Rorf118, hol and lys under } P_{\text {lac }} \text { ) }\end{array}$ & This work \\
\hline pL119XBL & $\begin{array}{l}\text { pUC119::2,338-bp XbaI-BamHI fragment from pL119PPR } \\
\text { (hol and lys under } P_{l a c} \text { ) }\end{array}$ & This work \\
\hline pL118EHL & $\begin{array}{l}\text { pUC118::1,760-bp EcoRI-HindIII fragment from pL119PPR } \\
\text { (lys under } P_{\text {lat }} \text { ) }\end{array}$ & This work \\
\hline pL119XSuL & $\begin{array}{l}\text { pUC1 19::530-bp XbaI-Sau3AI fragment from pL119PPR } \\
\text { (hol under } P_{\text {lac }} \text { ) }\end{array}$ & This work \\
\hline pL118XDL & $\begin{array}{l}\text { pUC118::732-bp Xbal-DraI fragment from pL119PPR } \\
\text { (hol and diys- } \Delta l a c Z^{\prime} \text { under } P_{l a c} \text { ) }\end{array}$ & This work \\
\hline pL118EDL & $\begin{array}{l}\text { pUC118::502-bp EcoRI-DraI fragment from pL118XDL } \\
\left(\text { Alys-Alac } Z^{\prime} \text { under } P_{l a c}\right)\end{array}$ & This work \\
\hline pL118EHiL & $\begin{array}{l}\text { pUC118::569-bp EcoRI-HinclI fragment from } \phi \mathrm{gle} \\
\left(\text { Rorf } 94 \text { under } P_{\text {lac }}\right)\end{array}$ & This work \\
\hline pL119PPR & pUCl19::2,963-bp Pst fragment from $\phi \mathrm{gle}$ & This work \\
\hline pL18DPR & pUC18::1,332-bp Pst I-Dral fragment from pL119PPR & This work \\
\hline pL18DPRdel & pUC18::1,296-bp PstI-DraI (436-bp HincII) fragment from pL118DPR & This work \\
\hline pL18EPR & pUC18::830-bp PstI-EcoRI fragment from pL119PPR & This work \\
\hline
\end{tabular}

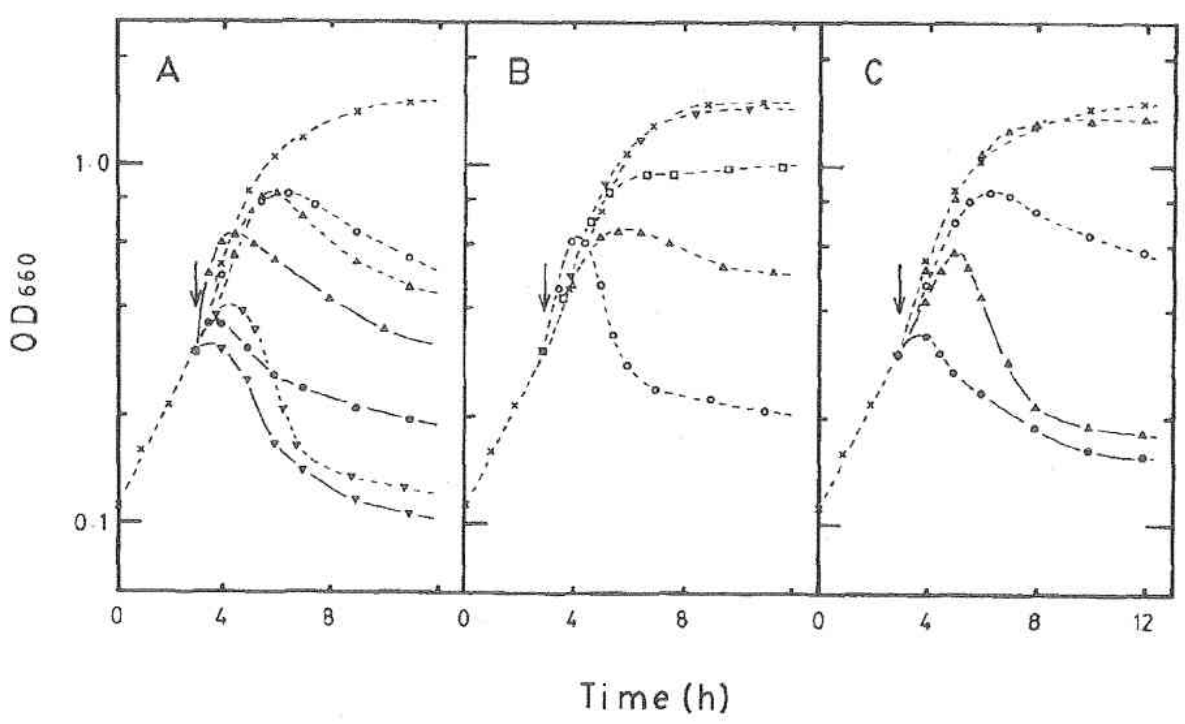

Fig. 6. Expression of the $\phi$ gle lysis genes in E. coli. (A) E. coli XL1-blue carrying the plasmid pL119XSuL (O, ㄱ) $)$ pL118EHL ( $\triangle$, $\triangle$ ), pL119XBL $(\nabla, \nabla)$ or the vector plasmid pUC118 or $119(x)$, was grown at $25^{\circ} \mathrm{C}$ in LB medium containing ampicillin $(60 \mu \mathrm{g} / \mathrm{ml})$. When the $\mathrm{A}_{660}$ of the culture had reached 0.3 , the growth temperature was shifted to $37^{\circ} \mathrm{C}$ with (open symbols) or without (filled symbols) concomitant addition of IPTG (final concentration $1 \mathrm{mM}$ ). Growth of the cells was monitored by measuring the change in $A_{660}$. (B) $E$. coli XL1-blue carrying the plasmid pL119PPR (O), pL18DPR $(\triangle)$, pL18DPRdel $(\square)$, pL18EPR $(\nabla)$ or the vector plasmid pUC18 or $119(\mathrm{X})$, was grown at $25^{\circ} \mathrm{C}$ in LB medium containing ampicillin $(60 \mu \mathrm{g} / \mathrm{ml})$. When the $\mathrm{A}_{660}$ of the culture had reached 0.3 , the growth temperature was sifted to $37{ }^{\circ} \mathrm{C}$, and the cell growth was monitored as indicated in (A). (C) E. coli XL1-blue carrying the plasmid pL118XDL (O, $)$, pL118EDL ( $\triangle$, $\triangle$ ) or the vector plasmid pUC118 (X), was grown at $25^{\circ} \mathrm{C}$ in LB medium containing ampicillin $(60 \mu \mathrm{g} / \mathrm{ml})$. When the $A_{660}$ of the culture had reached 0.3 , the growth temperature was shifted to $37^{\circ} \mathrm{C}$ with (open symbols) or without (filled symbols) concomitant addition of IPTG (final concentration $1 \mathrm{mM}$ ), and the cell growth was monitored as indicated in $(\mathrm{A})$.

1994). On the other hand, XL1-blue harboring pL18EPR or pL118EHiL grew normally, suggesting that each of gpRorf50, gpRorf118 and gpRorf94 can not disturb the cell envelope integrity for oneself.
Two recombinant plasmids pL118XDL and pL118EDL have a fused gene (under $\mathrm{p}_{\text {lac }}$ control), termed $\mathrm{DE} / \alpha$, which is composed of 78 -aa N-terminus of lysin and 91-aa C-terminus of lacZ' $\alpha$-fragment 
(Table 1 and Fig. 2). Upon temperature shift up from $30^{\circ}$ to $37^{\circ} \mathrm{C}$ in the absence of IPTG, pL118XDL carry. ing both of hol and $D E / \alpha$ manifested the turbidity decrease after $240 \mathrm{~min}$ (Fig. 6C), although the rate was somewhat low when compared with pL119XBL (hol-lys) (Fig. 6A), whereas pL118EDL harboring $D E / \alpha$ did not reduce the cellular turbidity (Fig. $6 \mathrm{C}$ ). When induced by IPTG at $37^{\circ} \mathrm{C}$, both of the recombinants exhibited a rapid onset of turbidity decrease: $h o l-D E / \alpha$, within $60 \mathrm{~min} ; \mathrm{DE} / \alpha$, within $120 \mathrm{~min}$. These results suggest that the module DE of $\phi$ gle lysin localized in its N-terminus (Fig. 3A and Fig. 5) contains an active center(s) for its lytic activity.

To estimate whether the $\phi$ g1e holin-lysin system can make a lesion(s) in E. coli cell wall (or membrane), release of a cytoplasmic enzyme $\beta$-galactosidase was measured at $37^{\circ} \mathrm{C}$ along with the turbidity drop of $E$. coli CK111 lacZ ${ }^{+}$carrying pL119PPR (Rorf50-Rorf118-hol$l y s$ ), which are free from laq $I^{q}$ control. As presented in Fig. $7, \beta$-galactosidase activity was found in the medium (120 $\mathrm{min}$ after the temperature shift), and its release from the cytoplasm correlated well with the rate of turbidity reduction.

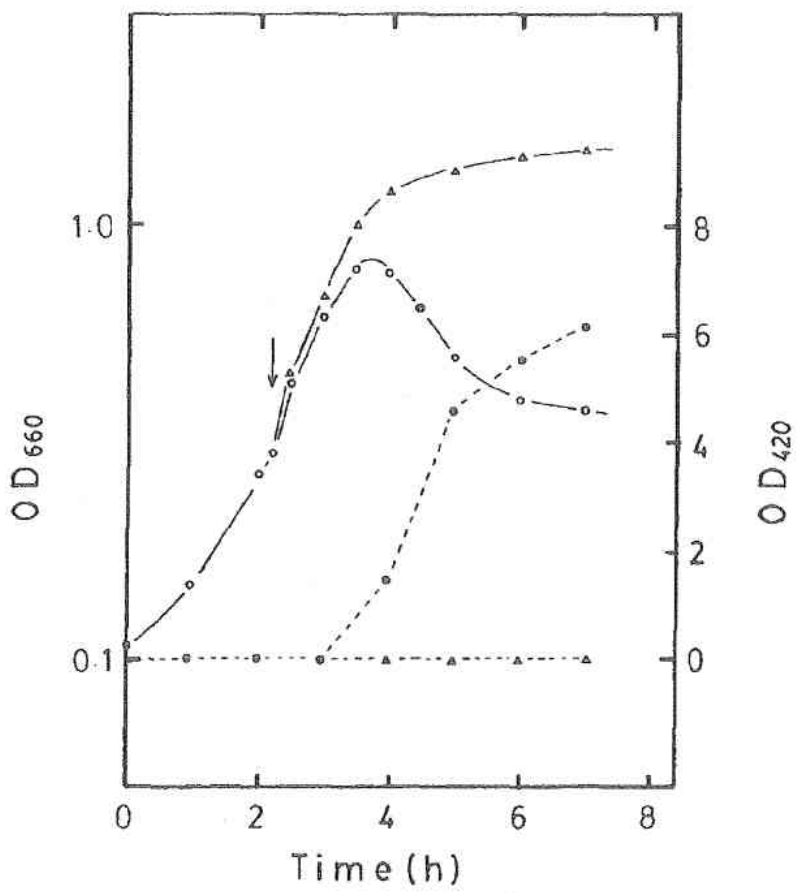

Fig. 7. Release of $\beta$-galactosidase by the $\phi \mathrm{gle}$ lysis system. E. coli CK111 carrying the plasmid pL19PPR $(O)$ or the vector plasmid pUC19 $(\triangle)$ was grown at $25^{\circ} \mathrm{C}$ in LB medium containing ampicillin $(60 \mu \mathrm{g} / \mathrm{ml})$. When the $A_{660}$ of the culture had reached 0.3 , the growth temperature was shifted to $37^{\circ} \mathrm{C}$, and the cell growth was monitored as indicated in Fig. 6. At intervals, a potion of the culture was removed, and the cell-free supernatant fluid was obtained by centrifugation. $\beta$-Galactosidase activity of the supernatant of the cells harboring PL19PPR () or the vector pUC19 (A) was monitored at $A_{420}$ as described in Section 2.
These observations in $E$. coli suggested that the two $\phi$ gle putative proteins, holin and lysin, can introduce a lesion(s) in the E. coli cell envelope, and the holin-lysin system is essentially involved in the cytolytic process. As in lambda (Young, 1992) and P2 (Ziermann et al., 1994), the $\phi \mathrm{g} 1 \mathrm{l}$ genes hol and lys might be under a complicated control. Further studies on structure, expression, function, and enzymatic properties of the $\phi \mathrm{g} 1 \mathrm{e}$ lysis genes are now in progress.

\section{Acknowledgements}

We thank Dr. S. Nakamura (Toyama, Japan), and Drs. Y. Masamune, and R. Hosono (Kanazawa, Japan) for encouragement and support.

\section{References}

Arendt, E.K., Daly, C., Fitzgerald, G.F. and van de Guchte, M. (1994) Molecular characterization of Lactococcal bacteriophage Tuc2009 and identification and analysis of genes encoding Lysin, a putative Holin, and two structural proteins. Appl. Environ. Microbiol. 60, 1875-1883.

Birkeland, N.-K. (1994) Cloning, molecular characterization, and expression of the genes encoding the lytic functions of lactococcal bacteriophage $\phi \mathrm{LC} 3$ : a dual lysis system of modular design. Can. J. Microbiol. 40, 658-665.

Boizet, B., Lahbib-Mansais, Y., Dupont, L., Ritzenthaler, P. and Mata, M. (1990) Cloning, expression and sequence analysis of an endolysin-encoding gene of Lactobacillus bulgaricus bacteriophage mv1. Gene 94, 61-67.

Burd, C.G. and Dreyfuss, G. (1994) Conserved structures and diversity of functions of RNA-binding proteins. Science 265, 615-621.

Campbell, A. (1994) Comparative molecular biology of lamboid phages. Annu. Rev. Microbiol. 48, 193-222.

Davidson, B.E., Powell, I.B. and Hillier, A.J. (1990) Temperate bacteriophages and lysogeny in lactic acid bacteria. FEMS Microbiol. Rev. 87, 79-90.

Dupont, L., Vasala, A., Mikkonen, M., Boizet-Bonhoure, B. Alatossava, T. and Ritzenthaler, P. (1993) GenBank accession No. Z26590.

Fouche, P.B. and Hash, J.H. (1978) The N,O-diacetylmuramidase of Chalaropsis species. Identification of aspartyl and glutamyl residues in the active site. J. Biol. Chem. 233, 6787-6793.

Garcia, P., Garcia, J.L., Garcia, E., Sanchez-Puelles, J.M. and Lopez, R. (1990) Modular organization of the lytic enzymes of Streptococcus pneumoniae and its bacteriophages. Gene 86, 81-88.

Harley, C.B. and Reynolds, R.P. (1987) Analysis of E. coli promoter sequences. Nucleic Acids Res. 15, 2343-2361.

Henrich, B., Binishofer, B. and Blasi, U. (1995) Primary structure and functional analysis of the lysis genes of Lactobacillus gasseri bacteriophage $\phi$ adh. J. Bacteriol. 177, 723-732.

Kakikawa, M., Oki, M., Tadokoro, H., Nakamura, S., Taketo, A. and Kodaira, K.-I. (1996) Cloning and nucleotide sequence of the major capsid protein of Lactobacillus bacteriophage $\phi \mathrm{g} l \mathrm{e}$. Gene (in press).

Kodaira, K.-I., Nakano, K., Okada, S. and Taketo, A. (1992) Nucleotide sequence of the genome of the bacteriophage $\alpha 3$ : interrelationship of the genome structure and the gene products with those of the phages, $\phi \times 174, \mathrm{G} 4$, and $\phi \mathrm{K}$. Biochim. Biophys. Acta 1130, 277-288.

Kodaira, K.-I., Oki, M., Taketo, A., Yasukawa, H. and Masamune, Y. 
(1994a) Determination of the single stranded origin of Shigella sonnei plasmid pKYM. Biochim. Biophys. Acta 1260, 183-190.

Kodaira, K.-I., Godson, G.N. and Taketo, A. (1994b) Comparative studies of the minus origin mutants of Escherichia coli spherical single-stranded DNA phages. Biochim. Biophys. Acta 1260, 191-199.

Ludwig, W., Seewaldt, E., Klipper-Balz, R., Schleiffer, K.H., Magrum, L., Woese, C.R., Fox, G.E. and Stackebrandt, E. (1985) The phylogenetic position of Streptococcus and Enterococcus. J. Gen. Microbiol. 131, 543-551.

Pouwels, P.H. and Lee, R.J. (1993) Genetics of lactobacilli: plasmid and gene expression. Antonie van Leeuwenhoek 64, 85-107.

Sable, S. and Lortal, S. (1995) The lysins of bacteriophages infecting lactic acid bacteria. Appl. Microbiol. Biotech. 43, 1-6.

Sambrook, J., Fritsch, E.F. and Maniatis, T. (1989) Molecular cloning: a laboratory manual, 2nd ed. Cold Spring Harbor Laboratory, Cold Spring Harbor, NY.

Sanger, F., Nicklen, S. and Coulson, A.R. (1977) DNA sequencing with chain-terminating inhibitors. Proc. Natl. Acad. Sci. USA 71, $5463-5467$.
Sanger, F, Coulson, A.R., Hill, D.F and Petersen, G.B. (1982) Nucleotide sequence of bacteriophage $\lambda$ DNA. J. Mol. Biol. $162,729-773$.

Schouler, C., Ehrlich, S.D. and Chopin, M.-C. (1994) Sequence and organization of the lactococcal prolate-headed bIL67 phage genome. Microbiology 140, 3061-3069.

Taketo, A. (1988) DNA transfection of Escherichia coli by electroporation. Biochim. Biophys. Acta 949, 318-324.

Terzaghi, B.E. and Sandine, W.E. (1975) Improved medium for lactic Streptococci and their bacteriophages. Appl. Microbiol. 29, 807-813. Vieira, J, and Messing, J. (1987) Methods Enzymol. 153, 3-11.

Young, R. (1992) Bacteriophage lysis: mechanism and regulation. Microbiol. Rev. 56, 430-481.

Ziermann, R., Bartlett, B., Calendar, R. and Christie, G.E. (1994) Functions involved in bacteriophage $\mathrm{P} 2$-induced host cell lysin and identification of a new tail gene. J. Bacteriol, 176, 4974-4984.

Zink, R., Loessner, M.J. and Scherer, S. (1995) Characterization of cryptic prophages (monocins) in Listeria and sequence analysis of a holin/endolysin gene. Microbiol. 141, 2577-2584. 